\title{
Antifungal activity of the cyanobacterium Microcystis aeruginosa against mycotoxigenic fungi
}

\author{
Diaa A. Marrez ${ }^{*}$, Yousef Y. Sultan \\ Marine Toxins Laboratory, Toxicology and Food Contaminants Department, National Research Centre, Cairo, Egypt.
}

\section{ARTICLE INFO \\ Article history: \\ Received on: 07/09/2016 \\ Revised on: 28/09/2016 \\ Accepted on: 18/10/2016 \\ Available online: 29/11/2016}

Key words:

Microcystis aeruginosa,

Antifungal activity,

mycotoxigenic fungi, TLC

bioautography.

\begin{abstract}
Cyanobacteria are rich sources of bioactive compounds. In the present study, the antifungal activity of different solvent extracts of Microcystis aeruginosa was evaluated. Among these extracts, diethyl ether extract showed the highest antifungal activity against all tested mycotoxigenic fungi and gave inhibition zone ranged from 10.3 to $21.6 \mathrm{~mm}$. In this direction, the fraction (F4) was the best fraction in antifungal activity against all tested fungi. Sub-fraction F4-10 was chosen as the highest sub-fraction had bioactivity. Using TLC bioautography, GC-MS and NMR; two antifungal compounds were isolated, purified and identified as Butylated Hydroxytoluene (BHT) and Hexadecanoic acid, methyl ester.
\end{abstract}

\section{INTRODUCTION}

Cyanobacteria are prokaryotic cells use chlorophyll for photosynthesis. Therefore, many species have capability for nitrogen fixation (Chronakis, 2000). They are found in a wide range of different habitats, including marine, hot springs, soils and hyper-saline environments (Colyer et al., 2005; Tiwari et al., 2005). Cyanobacteria appeared to be rich source of many useful products, which include various types of substances ranging from organic acids, carbohydrates, amino acids, peptides, vitamins, growth substances, antibiotics, enzymes and toxic compounds (Codd, 1997 and Carmichael, 2001). They can be also used as an animal feed and biofertilizer (Bano and Siddiqui, 2004). The biotechnological applications of cyanobacteria have been reported in diverse areas, such as agriculture, aquaculture, bioremediation, biofuels, pharmaceutical and nutraceuticals (Abed et al., 2009 and Pandey et al., 2013). A large number of cyanobacterial strains are known to produce intracellular and

* Corresponding Author

Diaa A. Marrez, Researcher at Marine Toxins Laboratory, Toxicology

and Food Contaminants Department, National Research Centre

Email:diaamm80@ hotmail.com extracellular metabolites with various biological activities, i.e. antibacterial, antifungal, antiviral, antialgal and antiprotozoal activity (Burja et al., 2001; Chlipala et al., 2009 and Sultan et al., 2016). These identified substances include fatty acids, phenolics, terpenoids, N-glycosides, lipopeptides, cyclic peptides and isonitrile-containing indole alkaloids (Mundt et al., 2003; Neuhof et al., 2005 and Mo et al., 2009). Moreover, cyanobacteria are produced toxins associated with water blooms. About 40 genera of cyanobacterial species are responsible for production of cyanobacterial toxins (Grindberg et al., 2008). These toxins can be classified according to their toxic mechanism in vertebrates as hepatotoxins, neurotoxins, irritants and dermatotoxins (Stewart et al., 2006). The genus Microcystis belong to the most common bloom forming cyanobacteria in many freshwater bodies worldwide and also occur in coastal brackish areas (Rybicka, 2005; Mazur et al., 2003). Microcystis aeruginosa is known to produce a large numbers of toxic or bioactive metabolites in freshwater environment. The majority of these compounds have ecological roles as allelochemical (Berry et al., 2008). These allelochemicals play a role in defense of $M$. aeruginosa against predators and gazers, especially aquatic invertebrates and larvae. 
Several foods and agricultural products are subject to contamination with mycotoxigenic fungi which cause varied troubles in both human and animal health. Therefore, there are many efforts towards finding new sources of antifungal metabolites as a natural fungicidal agent. The aim of the present work was to study the antifungal activity of $M$. aeruginosa extracts against several species of mycotoxigenic fungi. Furthermore, the work aimed to isolate, purify and structure elucidate of these antifungal compounds.

\section{MATERIALS AND METHODS}

\section{Organism and growth culture}

Pure strain of Microcystis aeruginosa was obtained from Marine Toxins lab., National Research Centre, Egypt (Marrez et al., 2016). The culture media used for cultivation of M. aeruginosa was BG-11 medium (Rippka et al., 1979). It composed of $1.5 \mathrm{~g}$ $\mathrm{NaNO}_{3} ; 0.004$ g $\mathrm{K}_{2} \mathrm{HPO}_{4} ; 0.075 \mathrm{~g} \quad \mathrm{MgSO}_{4} .7 \mathrm{H}_{2} \mathrm{O} ; 0.036 \mathrm{~g}$ $\mathrm{CaCl}_{2} .2 \mathrm{H}_{2} \mathrm{O} ; 0.006 \mathrm{~g}$ citric acid; $0.02 \mathrm{mg} \mathrm{Na} \mathrm{NO}_{2} ; 0.001 \mathrm{~g}$ $\mathrm{Na}_{2}$ EDTA; $0.63 \mathrm{~g}$ ferric ammonium citrate and $1.0 \mathrm{ml}$ trace elements (TE) in $1000 \mathrm{ml}$ distilled water. TE $(\mathrm{g} / \mathrm{l})$ is combined of $2.86 \mathrm{~g} \mathrm{H}_{3} \mathrm{BO}_{3} ; 1.81 \mathrm{~g} \mathrm{MnCl}_{2}$. $4 \mathrm{H}_{2} \mathrm{O} ; 0.222 \mathrm{~g} \mathrm{ZnSO}_{4} .7 \mathrm{H}_{2} \mathrm{O} ; 0.39 \mathrm{~g}$ $\mathrm{Na}_{2} \mathrm{MoO}_{4} . \quad 2 \mathrm{H}_{2} \mathrm{O} ; \quad 0.079 \mathrm{~g} \quad \mathrm{CuSO}_{4} . \quad 5 \mathrm{H}_{2} \mathrm{O}$ and $0.0494 \mathrm{~g}$ $\mathrm{Co}\left(\mathrm{NO}_{3}\right)_{2} \cdot 6 \mathrm{H}_{2} \mathrm{O}$. After autoclaving and cooling, $\mathrm{pH}$ was adjusted to 7.1 .

\section{Preparation of $M$. aeruginosa extracts}

At the stationary phase of growth (approximately 25 days), $M$. aeruginosa biomass was harvested and dried in a hot air oven at $50^{\circ} \mathrm{C}$ over night. The dried biomass $(5 \mathrm{~g})$ extracted with different solvent of aqueous, methanol, ethanol, acetone, chloroform, diethyl ether, ethyl acetate and hexane. The extracts were sonicated for $20 \mathrm{~min}$ using ultrasonic microtip probe of 400 watt and centrifuged at $4500 \mathrm{rpm}$ for $10 \mathrm{~min}$. Supernatant was retained and the pellet re-extracted as before three times. Combined supernatant was evaporated to dryness at $40^{\circ} \mathrm{C}$ using rotary evaporator. Dried extracts were stored in labeled sterile vials in a refrigerator till further use (Chauhan et al., 2010).

\section{Antifungal assay \\ Test microorganisms}

Nine fungal species were used for antifungal assay, Aspergillus flavus NRRL 3357, A. parasiticus SSWT 2999, A. westerdijikia CCT 6795, A. steynii IBT LKN 23096, A. ochraceus ITAL 14, A. carbonarius ITAL 204, Fusarium verticillioides ITEM 10027, $F$. proliferatum MPVP 328 and Penicillium verrucosum BFE 500. The fungal strains were obtained from Applied Mycology Dept., Cranfield Unvi., UK. The stock cultures were grown on potato dextrose agar slant at $25^{\circ} \mathrm{C}$ for 5 days and then kept in refrigerator till use.

\section{Media used for antifungal assay}

Yeast extract sucrose medium (YES) composed of $20 \mathrm{~g}$ yeast extract, $150 \mathrm{~g}$ sucrose and $20 \mathrm{~g}$ agar in $1000 \mathrm{ml}$ distilled water
(Tsubouchi et al., 1987) was used for fungal disc diffusion test. Potato dextrose agar medium (PDA) composed of potato $200 \mathrm{~g}$, dextrose $15 \mathrm{~g}$ and agar $20 \mathrm{~g}$ in $1000 \mathrm{ml}$ distilled water. The $\mathrm{pH}$ was adjusted to 7.0 (ATCC, 1984), for determination of minimum inhibitory concentration.

\section{Disc diffusion technique}

The fungal strains were plated onto potato dextrose agar (PDA) and incubated for 5 days at $25^{\circ} \mathrm{C}$. The spore suspension of each fungus was prepared in $0.01 \%$ Tween 80 solution. The concentration of spore suspension of each strain was adjusted by comparison with the 0.5 McFarland standard, the turbidity of the inoculum suspension represented approximately $2 \times 10^{8} \mathrm{cfu} \mathrm{ml}^{-1}$. Sterilized filter paper discs $(6 \mathrm{~mm})$ were loaded with the extracts and dried completely under sterile conditions. Petri dishes of YES medium were inoculated with $50 \mu$ of each fungal culture and uniformly spread using sterile L- glass rod. The extract loaded discs were placed on the seeded plates by using a sterile forceps. Negative control was prepared by using DMSO and the commercial fungicide Nystatin (1000 Unit $\mathrm{ml}^{-1}$ ) was used as a positive control.

The inoculated plates were incubated at $25^{\circ} \mathrm{C}$ for $24-48$ h. At the end of the period, antifungal activity was evaluated by measuring the zone of inhibition $(\mathrm{mm})$ against the tested fungus (Medeiros et al., 2011). All treatments consisted of three replicates and the averages of the experimental results determined.

\section{Determination of minimum inhibitory concentration (MIC)}

MIC against fungi was performed using the technique of Perrucci et al. (2004). Crude extracts at different concentrations were separately dissolved in $0.5 \mathrm{ml}$ of $0.1 \%$ Tween 80 (Merck, Darmstadt, Germany), then mixed with $9.5 \mathrm{ml}$ of melting, $45^{\circ} \mathrm{C}$, PDA and poured into Petri dish $(6 \mathrm{~cm})$. The prepared plates were centrally inoculated with $3 \mu$ l of fungal suspension. The plates were incubated at $25^{\circ} \mathrm{C}$ for $24-48 \mathrm{~h}$. At the end of the incubation period, mycelial growth was monitored and MIC was determined.

\section{Fractionation, isolation and structure elucidation of bioactive compounds \\ Column chromatography}

The diethyl ether extracts (DEE) was fractionated using column chromatography technique. Glass column (30 x 500mm) initially packed with $5 \mathrm{~g}$ anhydrous sodium sulphate followed by $30 \mathrm{~g}$ of silica gel (0.06 - $0.2 \mathrm{~mm}, 70$ - 230 mesh ASTM) using chloroform as a carrier solvent to create slurry. The stopcock was opened to allow the silica gel packing to settle, while the excess chloroform was drained. During draining, another $5 \mathrm{~g}$ anhydrous sodium sulphate was added to the top of silica gel to prevent column from drying.

A portion of DEE $(500 \mathrm{mg})$ in $10 \mathrm{ml}$ chloroform was loaded to the column and allowed to flow at a rate of a drop $\mathrm{sec}^{-1}$. The order of solvent of elution in column chromatography was fixed as chloroform: methanol (98:2), (95:5), (90:10), (80:20), 
(50:50), (25:75) and finally methanol $100 \%$ to give 7 fractions. The column fractions $(50 \mathrm{ml}$ each) were evaporated under vacuum and analysed for bioassay tests. The active fractions in bioassay tests were divided to sub-fractions by submitted to column chromatography to develop by its elution and divided in 10 subfractions (5 $\mathrm{ml}$ each).

\section{Thin layer chromatography (TLC)}

TLC was performed on aluminum plate $10 \times 10 \mathrm{~cm}$, silica gel 60 (Merck, Darmstadt, Germany). Sub-fractions were spotted $2 \mathrm{~cm}$ from the base of the plate and $1.5 \mathrm{~cm}$ intervals between spots. Fifty microliter of each active sub-fraction $(20 \mathrm{mg}$ $\mathrm{ml}^{-1}$ ) was spotted onto the silica gel plate and allowed to dry for a few minutes. Afterwards, the plate was developed and run to $6 \mathrm{~cm}$ distance from the spotting base line with toluene: methanol: acetone: acetic acid (15:2:1:1) in a previously saturated glass chamber at room temperature.

The developed plate was dried under normal air and the spots were read at $254 \mathrm{~nm}$ and $366 \mathrm{~nm}$ using $\mathrm{UV}$ chamber. The $\mathrm{R}_{\mathrm{f}}$ (retention factor) values of isolated compounds were determined by the following formula: $\mathrm{R}_{\mathrm{f}}=$ Distance traveled by extract/distance traveled by solvent system.

\section{TLC bioautography for bioactivity screening}

Bioautographic evaluation was conducted in order to check the antimicrobial activity of separated compounds on TLC plate. Previous developed TLC plates were sterilized by UV lamp for $30 \mathrm{~min}$ and placed on $15 \mathrm{ml}$ potato dextrose agar plate. Molten potato dextrose agar $20 \mathrm{ml}$ seeded with $1 \mathrm{ml}$ of spore suspension was poured on TLC plate. After agar got solidified the petri plates were kept at $4{ }^{\circ} \mathrm{C}$ for $3 \mathrm{~h}$ and incubated at $25^{\circ} \mathrm{C}$ for $24-48 \mathrm{~h}$. The inhibition zones were detected by staining with iodonitrotetrazolium chloride reagent $2 \%$ (INT). After spraying with INT, the inhibition zones appear as clear spots against the red background (Hamburger and Cordell, 1987). The inhibition zones were compared with the $\mathrm{R}_{\mathrm{f}}$ values of the control TLC plate so that the active compounds were located on TLC.

Active bands were scratched from several TLC plates, dissolved in diethyl ether and filtrated to discard silica gel. Its purity as a single spot was confirmed by re-chromatographed on TLC with the same elution solvent system to make sure that is one single compound.

\section{Structure elucidation of the isolated bioactive compounds GC-MS analysis}

The GC/MS analysis was performed using a Thermo Scientific, Trace GC Ultra / ISQ Single Quadrupole MS, TG-5MS fused silica capillary column $(30 \mathrm{~m}, 0.251 \mathrm{~mm}, 0.1 \mathrm{~mm}$ film thickness). For GC/MS detection an electron ionization system with ionization energy of $70 \mathrm{eV}$ was used, Helium gas was used as the carrier gas at a constant flow rate of $1 \mathrm{ml} \mathrm{min-1.} \mathrm{The} \mathrm{injector}$ and MS transfer line temperature was set at $280 \mathrm{C}$.

The oven temperature was programmed at an initial temperature $50 \mathrm{C}$ (hold $2 \mathrm{~min}$ ) to $150^{\circ} \mathrm{C}$ at an increasing rate of $7^{\circ} \mathrm{C}$ $\min ^{-1}$, then to $270 \mathrm{C}$ at an increasing rate $5^{\circ} \mathrm{C} \min ^{-1}$ (hold $2 \mathrm{~min}$ ) then to 310 as a final temperature at an increasing rate of $3.5^{\circ} \mathrm{C}$ $\min ^{-1}$ (hold $10 \mathrm{~min}$ ).

The quantification of all the identified components was investigated using a percent relative peak area. A tentative identification of the compounds was performed based on the comparison of their relative retention time and mass spectra with those of the NIST, WILLY library data of the GC/MS system.

\section{Nuclear magnetic resonance (NMR)}

NMR spectra were acquired in DMSO-d6 on a Jeol ECA $500 \mathrm{MHz}$ NMR spectrometer, at $500 \mathrm{MHz}$. Standard pulse sequence and parameters were used to obtain one-dimensional ${ }^{1} \mathrm{H}$ and ${ }^{13} \mathrm{C} .{ }^{1} \mathrm{H}$ chemical shifts $(\delta)$ were measured in ppm, relative to TMS and ${ }^{13} \mathrm{C}$ NMR chemical shifts to DMSO-d6 and were converted to TMS scale by adding 29.8 .

\section{RESULTS AND DISCUSSION}

\section{Microcystis aeruginosa crude extracts}

Antifungal activity of $M$. aeruginosa extracts against different species of mycotoxigenic fungi is shown in Table (1). The diethyl ether extracts showed the best antifungal activity against all tested fungi achieving inhibition zone in range between $10.3 \mathrm{~mm}$ against A. flavus to $21.6 \mathrm{~mm}$ against $F$. verticillioides. A. flavus was the most sensitive fungus affected by all extracts with exception of methanol extract. However, A. ochraceus and $P$. verrucosum were tolerant of resistance to all $M$. aeruginosa extracts with exception of diethyl ether extract which had inhibition zone 20.0 and $16.8 \mathrm{~mm}$, respectively.

Several studies examined the activity of $M$. aeruginosa extracts against fungi. Khalid et al. (2010) reported that Microcystis aeruginosa methanolic extract exhibited strong antifungal activity against 20 fungal species included 7 human pathogens and 5 plant pathogens.

Madhumathi et al. (2011) found that M. aeruginosa methanol, ethanol, acetone and diethyl ether extracts had the largest antifungal activity against C.ablicans and S. cerevisiae. Also, Salem et al. (2014) indicated that Microcystis sp. acetone extract showed antifungal activity against $A$. niger. Shrivastava (2014) found that M. aeroginosa methanolic extract significantly inhibited the mycelial growth of Aspergillus fumagatus, Candida albicans and Rhizoctonia solani. Jaiswal et al. (2011) revealed that M. aeruginosa dichloromethane and ethyl acetate extracts had antifungal activity against the phytopathogenic fungus Rhizoctonia solani. Perveen and Alwathani (2013) found that methanol extract M. aeroginosa showed antifungal activity against Fusarium sp., $F$. oxysporum, $F$. solani and A. flavus, while acetone had antifungal against F. solani. Moreover, Kulik (1995) reported that cyanobacterial culture filtrates or cell extracts were applied to seeds for protect them against Fusarium sp. and Rhizoctonia solani. 
Table 1: Antifungal activity of Microcystis aeruginosa crude extracts.

\begin{tabular}{|c|c|c|c|c|c|c|c|c|c|}
\hline \multirow{2}{*}{ Fungi } & \multicolumn{9}{|c|}{ Inhibition zone $\mathrm{mm}($ Mean \pm S.E. $)$} \\
\hline & -ve control & +ve control & $\mathrm{MeOH}$ & EtOH & Acetone & $\mathrm{CH}_{3} \mathrm{Cl}$ & DEE & EtOA & Hexane \\
\hline A. flavus & 0 & $16.1 \pm 0.74$ & 0 & $7.2 \pm 0.28$ & $9.3 \pm 0.89$ & $8.7 \pm 0.28$ & $10.3 \pm 1.25$ & $8.0 \pm 0.5$ & $9.8 \pm 1.15$ \\
\hline A. niger & 0 & $7.5 \pm 0.35$ & $8.0 \pm 0.50$ & $7.5 \pm 0.50$ & $8.2 \pm 0.28$ & 0 & $13.7 \pm 1.56$ & $11.3 \pm 1.04$ & 0 \\
\hline A. ochraceus & 0 & $10.9 \pm 0.54$ & 0 & 0 & 0 & 0 & $20.0 \pm 1.50$ & 0 & 0 \\
\hline A. parasiticus & 0 & $11.8 \pm 2.01$ & 0 & $7.7 \pm 0.58$ & 0 & $8.2 \pm 0.76$ & $13.3 \pm 1.25$ & $9.3 \pm 0.76$ & 0 \\
\hline A. westerdijikia & 0 & $10.5 \pm 0.35$ & 0 & 0 & 0 & 0 & $10.2 \pm 0.76$ & $8.0 \pm 0.50$ & 0 \\
\hline A. Carbonarius & 0 & $10.4 \pm 0.41$ & $9.8 \pm 1.15$ & 0 & 0 & 0 & $10.5 \pm 1.80$ & $7.7 \pm 0.28$ & 0 \\
\hline F. verticillioides & 0 & $11.0 \pm 0.35$ & 0 & 0 & 0 & 0 & $21.6 \pm 0.75$ & $7.2 \pm 0.78$ & 0 \\
\hline F. Proliferatum & 0 & $11.0 \pm 0.61$ & 0 & 0 & $10.2 \pm 1.04$ & $9.8 \pm 1.04$ & $17.8 \pm 1.25$ & 0 & 0 \\
\hline P. verrucosum & 0 & $9.9 \pm 1.43$ & 0 & 0 & 0 & 0 & $16.8 \pm 0.76$ & 0 & 0 \\
\hline
\end{tabular}

n=3, *S.E: standard error, 0: No inhibition, MeOH: methanol, EtOH: ethanol, DEE: diethyl ether, EtOA: ethyl acetate, negative control: DMSO, positive control: Nystatin.

Table 2: Antifungal activity of Microcystis aeruginosa diethyl ether fractions.

\begin{tabular}{|c|c|c|c|c|c|c|c|c|}
\hline \multirow[t]{2}{*}{ Fungi } & \multicolumn{8}{|c|}{ Inhibition zone mm (Mean \pm S.E.) } \\
\hline & Control & F1 & F2 & F3 & F4 & F5 & F6 & F7 \\
\hline A. flavus & 0 & $8.3 \pm 1.15$ & $9.0 \pm 2.00$ & 0 & $8.0 \pm 0.00$ & 0 & 0 & 0 \\
\hline A. steynii & 0 & $7.0 \pm 0.00$ & 0 & 0 & $7.7 \pm 0.58$ & 0 & 0 & 0 \\
\hline A. ochraceus & 0 & $9.3 \pm 1.52$ & 0 & $7.3 \pm 0.58$ & $10.7 \pm 0.58$ & 0 & 0 & 0 \\
\hline A. parasiticus & 0 & 0 & $9.3 \pm 1.52$ & 0 & $7.2 \pm 0.76$ & $8.3 \pm 1.15$ & $7.7 \pm 0.15$ & 0 \\
\hline A. westerdijikia & 0 & 0 & 0 & 0 & $9.7 \pm 1.15$ & 0 & $8.0 \pm 0.00$ & $8.3 \pm 0.58$ \\
\hline A. Carbonarius & 0 & 0 & 0 & 0 & $8.3 \pm 0.58$ & 0 & $8.0 \pm 0.00$ & 0 \\
\hline F. verticillioides & 0 & 0 & $7.0 \pm 0.00$ & $7.3 \pm 0.58$ & $7.7 \pm 0.28$ & 0 & 0 & 0 \\
\hline F. Proliferatum & 0 & 0 & 0 & 0 & $8.0 \pm 1.00$ & $9.3 \pm 1.08$ & 0 & 0 \\
\hline P. verrucosum & 0 & $8.7 \pm 0.58$ & $8.7 \pm 0.28$ & $8.3 \pm 1.52$ & $8.3 \pm 0.58$ & 0 & $7.3 \pm 0.58$ & 0 \\
\hline
\end{tabular}

$\mathrm{n}=3, *$ S.E: standard error, 0 : No inhibition

Table 3: Antifungal activity of Microcystis aeruginosa sub-fraction F4

\begin{tabular}{|c|c|c|c|c|c|c|c|c|c|c|}
\hline \multirow[t]{2}{*}{ Fungi } & \multicolumn{10}{|c|}{ Inhibition zone mm (Mean \pm S.E. $)$} \\
\hline & F4-1 & F4-2 & F4-3 & F4-4 & F4-5 & F4-6 & F4-7 & F4-8 & F4-9 & F4-10 \\
\hline A. flavus & 0 & 0 & 0 & $9.7 \pm 1.15$ & $8.7 \pm 1.52$ & $10.3 \pm 2.31$ & 0 & $8.3 \pm 0.58$ & $7.0 \pm 0.00$ & $8.0 \pm 1.00$ \\
\hline A. steynii & 0 & 0 & $7.3 \pm 0.58$ & 0 & $7.7 \pm 1.15$ & $8.0 \pm 1.00$ & 0 & 0 & $7.7 \pm 1.15$ & $7.0 \pm 0.00$ \\
\hline A. ochraceus & $7.7 \pm 1.15$ & $8.0 \pm 1.00$ & 0 & $9.0 \pm 1.64$ & $8.0 \pm 1.73$ & $9.3 \pm 1.52$ & 0 & 0 & $8.3 \pm 0.58$ & $9.3 \pm 1.15$ \\
\hline A. parasiticus & 0 & 0 & $8.7 \pm 0.58$ & 0 & $8.3 \pm 1.15$ & $7.0 \pm 0.00$ & $7.7 \pm 1.15$ & $8.3 \pm 0.58$ & -- & $8.7 \pm 0.58$ \\
\hline A. westerdijikia & 0 & $7.7 \pm 0.58$ & 0 & 0 & $9.0 \pm 1.73$ & $8.7 \pm 1.15$ & $10.0 \pm 1.52$ & 0 & $8.3 \pm 1.15$ & $10.3 \pm 2.08$ \\
\hline A. Carbonarius & 0 & 0 & 0 & $8.3 \pm 0.58$ & $9.3 \pm 1.52$ & $8.7 \pm 0.58$ & $8.33 \pm 1.15$ & 0 & $8.3 \pm 0.58$ & $10.0 \pm 2.00$ \\
\hline F. verticillioides & $8.0 \pm 1.73$ & 0 & $8.0 \pm 0.00$ & $7.7 \pm 1.15$ & $7.0 \pm 0.00$ & $8.3 \pm 1.15$ & 0 & 0 & $6.8 \pm 0.28$ & $7.7 \pm 0.58$ \\
\hline F. Proliferatum & 0 & 0 & 0 & $8.0 \pm 1.00$ & 0 & 0 & $7 . .7 \pm 0.58$ & $8.7 \pm 1.52$ & $7.0 \pm 0.00$ & $10.3 \pm 1.21$ \\
\hline P. verrucosum & 0 & 0 & 0 & $7.7 \pm 1.15$ & $7.3 \pm 0.58$ & $7.7 \pm 1.15$ & $8.0 \pm 1.00$ & $7.7 \pm 1.15$ & $8.0 \pm 1.00$ & $8.3 \pm 1.15$ \\
\hline
\end{tabular}

$\mathrm{n}=3$, *S.E: standard error, 0: No inhibition.

\section{Microcystis aeruginosa diethyl ether fractions}

The antifungal activity of $M$. aeruginosa DEE fractions against nine mycotoxigenic fungi is represented in Table (2). Fraction F4 had antifungal activity against all tested fungi. In contrast, F7 showed no activity against tested fungi except $A$. westerdijikia with inhibition zone of $8.3 \mathrm{~mm}$. The highest antifungal activity was observed using F4 against $A$. ochraceus with inhibition zone of $10.7 \mathrm{~mm}$ followed A. carbonarius with inhibition zone of $9.7 \mathrm{~mm}$. Perveen and Alwathani (2013) indicated that methanol: acetone: diethyl ether $(5: 2: 1)$ extract observed strong inhibitory effect against $F$. solani and Cladosporium sp., and moderate activity against Fusarium sp. and F. oxysporum. Kamble et al. (2012) revealed that the diethyl ether extract of $M$. aeroginosa had the largest inhibition zone against $S$. cerevisiae and $C$. albicans on the agar.

\section{Microcystis aeruginosa diethyl ether sub-fractions}

Based on the results of antifungal activity of $M$. aeruginosa diethyl ether fractions, the active fractions against all tested fungi were fractionated into sub-fractions to increase the probability of bioactive compounds isolation and by disposing the sub-fractions that had no activity against the tested microorganisms. F4 was separated into 10 sub-fractions (F4-1 to F4-10). All obtained sub-fractions were evaluated for their antifungal activity.

Table (3) shows the antifungal activity of $M$. aeruginosa DEE fraction F4. Sub-fraction F4-10 showed antifungal activity against all tested fungi followed by F4-5 and F4-6 which had antifungal activity against all tested fungi except $F$. Proliferatum. The highest antifungal activity was recorded in F4-6 against $A$. flavus and F4-10 against $A$. westerdijikia and F. Proliferatum with inhibition zone of $10.3 \mathrm{~mm}$.

\section{Identification of compounds in Sub-fraction F4-10 using GC- MS}

Totally 7 compounds were identified by GC-MS from $M$. aeruginosa sub-fraction F4-10. These compounds were 9,12Octadecadienoic acid (Z,Z)- with peak area percent $7.57 \%$, Butylated hydroxytoluene $13.40 \%$, Pentadeconic acid,4- hexadecyl ester $5.70 \%$, Hexadecadienoic acid, methyl ester $27.44 \%$, 9- 
Octadecadienoic acid Z-(CAS) $10.77 \%$, Heptadecane $5.37 \%$ and 3-Methyl-2-butanol 2.11\% (Fig. 1 and Table 4).

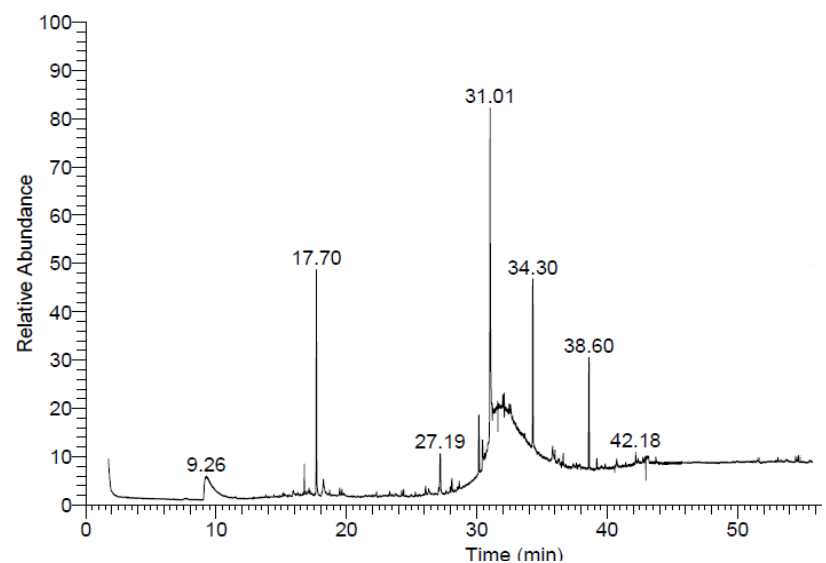

Fig. 1: GC-MS chromatogram of M. aeruginosa DEE extract sub-fraction F410.

Table 4: Components detected in sub-fraction F4-10 of $M$. aeruginosa DEE extract.

\begin{tabular}{llllll}
\hline No & RT & Compound & $\begin{array}{l}\text { Area } \\
\text { \% }\end{array}$ & $\begin{array}{l}\text { Molecular } \\
\text { formula }\end{array}$ & MW \\
\hline 1 & 9.26 & 9,12-Octadecadienoic acid (Z,Z)- & 7.57 & $\mathrm{C}_{18} \mathrm{H}_{32} \mathrm{O}_{2}$ & 280 \\
2 & 17.70 & Butylated hydroxy toluene & 13.40 & $\mathrm{C}_{15} \mathrm{H}_{24} \mathrm{O}$ & 220 \\
3 & 27.19 & Pentadeconic acid,4- hexadecyl ester & 5.70 & $\mathrm{C}_{15} \mathrm{H}_{30} \mathrm{O}_{2}$ & 242 \\
4 & 31.01 & Hexadecadienoic acid, methyl ester & 27.44 & $\mathrm{C}_{15} \mathrm{H}_{30} \mathrm{O}_{2}$ & 270 \\
5 & 34.30 & 9-Octadecadienoic acid Z-(CAS) & 10.77 & $\mathrm{C}_{18} \mathrm{H}_{34} \mathrm{O}_{2}$ & 282 \\
6 & 38.60 & Heptadecane & 5.37 & $\mathrm{C}_{17} \mathrm{H}_{36}$ & 240 \\
7 & 42.18 & 3-Methyl-2-butanol & 2.11 & $\mathrm{C}_{5} \mathrm{H}_{12} \mathrm{O}$ & 88 \\
\hline
\end{tabular}

Marimuthu et al. (2014) indicated that the fatty acids Hexadecanoic acid methyl ester, 9-Octadecenoic acid and 9,12Octadecadienoic acid $(\mathrm{Z}, \mathrm{Z})$ extracted from dry Christmas lima bean had antifungal activity against $A$. flavus and A. niger. Also in this direction, Ahmed et al. (2012) revealed that 9-Octadecenoic acid from the lipid extract of medicinal plant Acacia modesta had antifungal activity against $A$. flavus and $F$. solani as well as cytotoxic activity against Artemia salina. Demirel et al. (2011) and Mavi et al. (2011) indicated that Butylated hydroxytoluene from medicinal plants methanolic extract had antifungal activity against $C$. albicans. Mubarak et al. (2012) found that the fatty acid 9-Octadecenoic acid from lipid extract of Scenedesmus bijugatus had antimicrobial activity against $S$. aureus, E. coli and $C$. albicans. Udgire and Pathade (2013) reported that Pentadeconic acid, 4- hexadecyl ester which isolated from the medicinal plant Valeriana wallichii showed had antimicrobial activity against $K$. pneumonia, E. coli, S. aureus, P. aeruginosa and A. niger. Kumar et al. (2011), Jain et al. (2012) and Govindappa et al. (2014) reported that 9-Octadecenoic acid, methyl ester and 9,12Octadecadienoic acid, methyl ester isolated from some plants and Spirulina platensis display antibacterial and antifungal activity against several human pathogenic microorganisms.

\section{Detection of bioactive compounds in sub-fraction F4-10 by TLC bioautography}

Five clear and distinct bands were isolated from subfraction F4-10 using the solvent elution system toluene: methanol: acetone: acetic acid at ratio of 15:2:1:1 with retention factor values $\left(R_{f}\right)$ of $0.48,0.55,0.62,0.66$ and 0.71 . The bioautography of separated bands on TLC was used to detect the bioactivities of these bands against tested fungal strains. Table (5) illustrates TLC bioautography of $M$. aeruginosa sub-fraction F4-10 bands against 9 mycotoxigenic fungi. The spots of $\mathrm{R}_{\mathrm{f}} 0.55$ and 0.71 showed clear inhibition zone against all tested fungi followed by spot of $\mathrm{Rf} 0.66$ which had antifungal activity against tested fungi except $A$. ochraceus and $F$. proliferatum. No antifungal activities were observed in bands of $\mathrm{R}_{\mathrm{f}}$ values 0.48 .

Table 5: Inhibition of fungal growth on bioautographic TLC plates by $M$. aeruginosa diethyl ether sub-fraction F4-10.

\begin{tabular}{lllllll}
\hline \multicolumn{1}{c}{ Fungi } & \multicolumn{5}{c}{$\mathbf{R}_{\mathbf{f}}$ (Retention factor) } \\
\cline { 2 - 6 } & & $\mathbf{0 . 4 8}$ & $\mathbf{0 . 5 5}$ & $\mathbf{0 . 6 2}$ & $\mathbf{0 . 6 6}$ & $\mathbf{0 . 7 1}$ \\
\hline A. flavus & -- & ++ & ++ & + & +++ \\
A. steynii & -- & ++ & + & + & +++ \\
A. ochraceus & -- & +++ & -- & -- & ++ \\
A. parasiticus & -- & +++ & + & ++ & ++ \\
A. westerdijikia & -- & +++ & ++ & + & + \\
A. carbonarius & -- & ++ & -- & + & +++ \\
F. verticillioides & -- & ++ & -- & + & +++ \\
F. proliferatum & -- & +++ & -- & -- & ++ \\
$P$. verrucosum & -- & ++ & ++ & ++ & +++ \\
\hline (--): No inhibition, (+): inhibition zone $2-5 \mathrm{~mm},(++)$ : inhibition zone $5-7 \mathrm{~mm}$, \\
(+++): inhibition zone $>$ 7mm.
\end{tabular}

\section{Identification of antifungal compounds}

Based on bioautography assay, Spots of $R_{\mathrm{f}} 0.55$ and 0.71 in sub-fraction F4-10 were selected according to their high activity against all tested fungi.

\section{Structure elucidation of compound $A$}

Compound $\mathrm{R}_{\mathrm{f}} 0.55 \mathrm{~A}\left(\mathrm{R}_{\mathrm{f}} 0.55\right)$ had a molecular weight of 220 Dalton and chemical structure $\mathrm{C}_{15} \mathrm{H}_{24} \mathrm{O}$ based on GC-MS analysis (Fig. 2) (Saittagaroon et al., 1984 and Ruan et al., 2014).

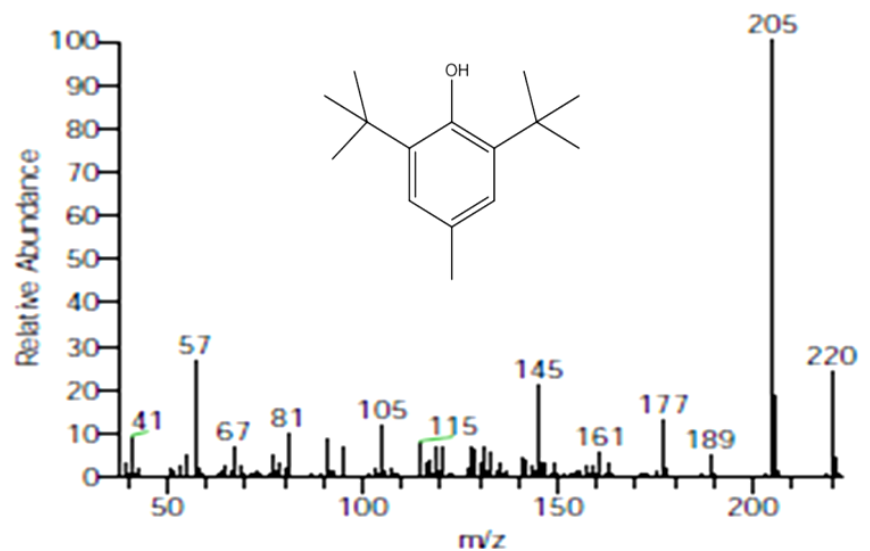

Fig. 2: GC-MS spectrum and chemical structure of Butylated Hydroxytoluene.

${ }^{1} \mathrm{H}-\mathrm{NMR}$ spectrum of compound $\mathrm{A}$ was measured in $\mathrm{CDCl}_{3}$ at $500 \mathrm{MHz}$ and revealed characteristic of Butylated Hydroxytoluene (BHT) as follow; two aliphatic singlet resonances at $\delta$ ppm $1.52(\mathrm{~s}, 18 \mathrm{H})$ attributed to two t-butyl groups, $\delta$ ppm 2.28 (s, 3H) belonging to $\mathrm{CH}_{3}$ attached to phenyl moiety. In addition to one aromatic signal at $\delta \mathrm{ppm} 7.03(\mathrm{~s}, 2 \mathrm{H})$ attributed to two 
aromatic protons and another signal $\delta \mathrm{ppm} 5.01(\mathrm{~s}, 1 \mathrm{H})$ which disappeared on addition of drop of $\mathrm{D}_{2} \mathrm{O}$ suggesting that it is belonging to the phenolic $\mathrm{OH}$. So, the structure of compound $\mathrm{A}$ is confirmed to be (BHT) 2,6-di t-butyl-4-methyl phenol (Silva et al., 2009 and Hwang et al., 2014). Passone et al. (2007) found that phenolic antioxidants such as butylated hydroxyanisole (BHA), butylated hydroxytoluene (BHT) and propyl paraben (PP) caused inhibition to Aspergillus growth at in vitro level. Also, Passone et al. (2008) found that a mixture of BHA, PP and BHT was more effective than the individual components in controlling the growth and AFB1 accumulation by Aspergillus section Flavi on peanuts. Demirel et al. (2011) and Mavi et al. (2011) indicated that Butylated hydroxytoluene from medicinal plants methanolic extract had antimicrobial activity against $E$. coli, $P$. aeruginosa, $S$. aureus and C. albicans.

\section{Structure elucidation of compound $B$}

Fig. (3) illustrates the chemical structure of compound B $\left(\mathrm{R}_{\mathrm{f}}\right.$ 0.71). According to GC-MS spectrum analysis the peak exhibited at 26.98 min retention time had a molecular weight 270 Dalton and chemical structure $\mathrm{C}_{17} \mathrm{H}_{34} \mathrm{O}_{2}$ (Abubacker and Deepalakshmi, 2013; Li et al., 2013; He et al., 2014). ${ }^{1} \mathrm{H}-\mathrm{NMR}$ confirmed the structure by diagnostic signals at $\delta=2.4-2.7 \mathrm{ppm}$ $(2 \mathrm{H}, \mathrm{d}), \delta=1.53 \mathrm{ppm}(2 \mathrm{H}, \mathrm{m}), \delta=1.2 \mathrm{ppm}(26 \mathrm{H}, \mathrm{m})$ and $\delta=3.54$ ppm $(3 \mathrm{H}, \mathrm{s})$. So, the structure of compound B was Hexadecanoic acid methyl ester (Saxena et al., 2007 and Oyugi et al., 2011). Most studies done to isolate and identify this compound were from plants. Prabhadevi et al. (2012) and Mujeeb et al. (2014) reported that hexadecanoic acid methyl ester which isolated from different plants showed antioxidant, anti-inflammatory, antibacterial, anticandidal, antifungal and cancer preventive activities. Also, Senthilkumar et al. (2013) reported that hexadecanoic acid methyl ester isolated from leaf extract of medicinal plant Ruellia tuberosa had antimicrobial activity against E. coli, P. aeruginosa, K. pneumonia, B. subtilis, Penicillium sp. and
Aspergillus sp. Lakshmi and Rajalakshmi (2011) indicated that hexadecanoic acid methyl ester possessed antioxidant, nematicidal and pesticidal activities. However, in similar study Khalid et al. (2010) isolated hexadecanoic acid methyl ester from toxic cyanobacteria Microcystis aeruginosa. They found that it had antibacterial activity against $B$. cereus, E. coli, K. pneumonia, S. aureus, S. typhi and V. choleriae.

\section{Minimum inhibitory concentration (MIC) values}

As shown in Table (6) the highest activity of $M$. aeruginosa DEE was recorded against $F$. verticillioides followed by $F$. proliferatum with MIC value of 0.62 and $0.66 \mathrm{mg} \mathrm{ml}^{-}$ ${ }^{1}$ medium, respectively. Whereas, the lowest activity was showed against $A$. ochraceus with MIC values $1.28 \mathrm{mg} \mathrm{ml}^{-1}$. M. aeruginosa $\mathrm{F} 4$ showed highest activity against $A$. westerdijikia with MIC of $0.8 \mathrm{mg} \mathrm{ml}^{-1}$. The highest activity of sub-fraction F410 was showed against $A$. flavus with MIC value of $0.75 \mathrm{mg} \mathrm{ml}^{-1}$. MIC values of BHT (compound A) against tested fungi ranged from 1.98 to $3.78 \mathrm{mg} \mathrm{ml}{ }^{-1}$. While, the MIC values of Hexadecanoic acid methyl ester (compound B) ranged from 0.82 to $1.3 \mathrm{mg} \mathrm{ml}^{-}$. It should be noticed that MIC values of diethyl ether crude extract were lower than fraction, sub-fraction and both purified compounds. This activity might be attributed to the synergistic effect of different compounds in crude extract ether than each compound alone. No available studies measured MIC of extracts, fractions, sub-fractions and pure compounds from $M$. aeruginosa, whereas other organisms were studied. Jassbi et al. (2013) indicated that Hexadecanoic acid methyl ester from a red algae Hypneaflagelli formis and two brown algae Cystoseiramyrica and Sargassum boveanum had antimicrobial activity against $E$. coli, $K$. pneumonia, S. typhi, S. aureus, $S$. epidemidis, B. subtilis, A. niger and C. albicans with MIC values ranged from 3 to $45.5 \mu \mathrm{g} \mathrm{ml}{ }^{-1}$. Al-Rekabi (2011) reported that Oscillatoria irrigua aqueous fraction had antifungal activity against $A$. flavus with MIC value $1.25 \mathrm{mg} \mathrm{ml}^{-1}$.

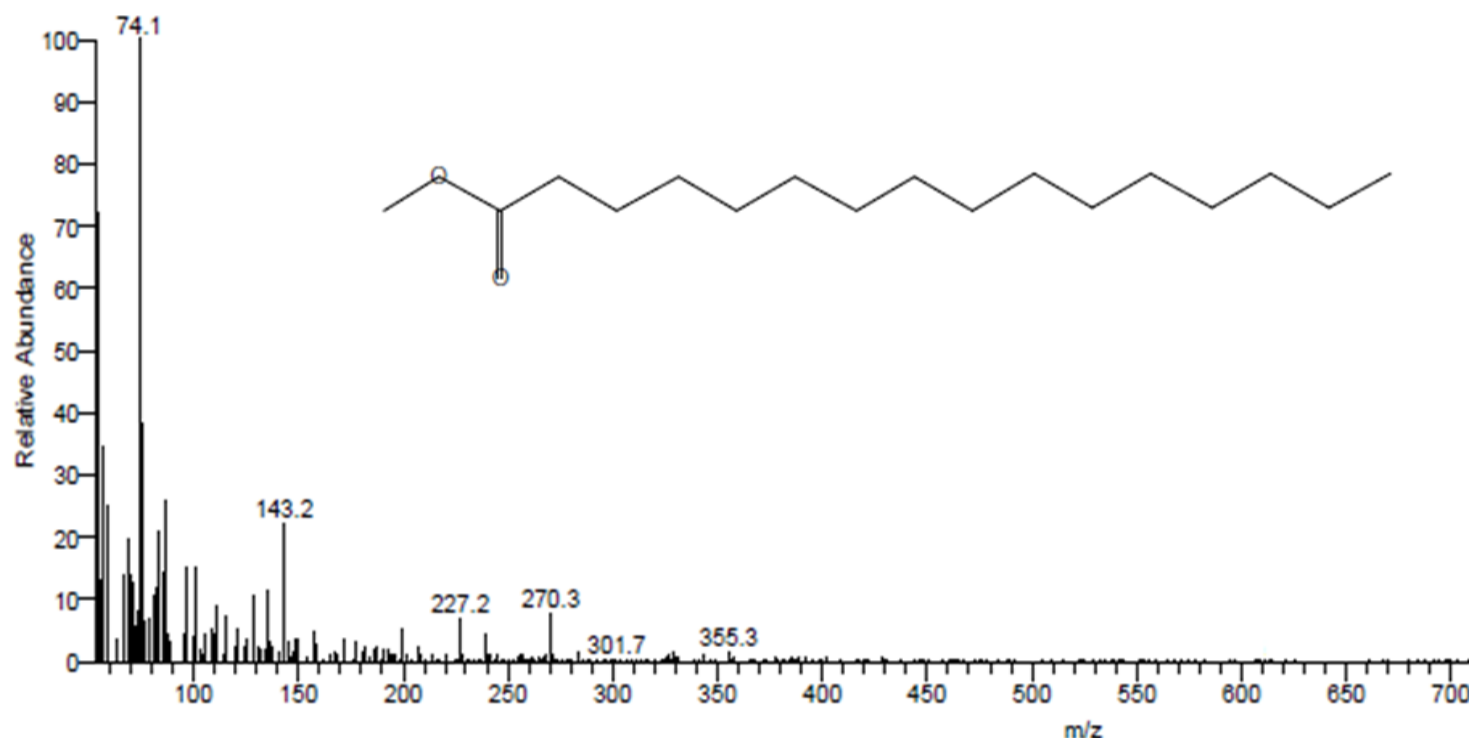

Fig. 3: GC-MS spectrum and chemical structure of Hexadecanoic acid, methyl ester. 
Table 6: MIC values (mg ml${ }^{-1}$ ) of M. aeruginosa DEE, fraction F4, sub-fraction F4-10, compound A and B.

\begin{tabular}{lcccc}
\hline \multirow{2}{*}{ Fungi } & \multicolumn{3}{c}{ MIC values mg ml $^{-\mathbf{1}}$ (Mean \pm S.E. $)$} \\
\cline { 2 - 5 } & DEE $^{*}$ & F4 & F4-10 & Compound A \\
\hline A. flavus & $0.74 \pm 0.21$ & $1.60 \pm 0.28$ & $0.75 \pm 0.14$ & $2.24 \pm 0.28$ \\
A. steynii & $0.82 \pm 0.14$ & $1.35 \pm 0.21$ & $1.15 \pm 0.21$ & $1.98 \pm 0.14$ \\
A. ochraceus & $1.28 \pm 0.14$ & $1.40 \pm 0.14$ & $1.32 \pm 0.14$ & $3.12 \pm 0.21$ \\
A. parasiticus & $0.88 \pm 0.28$ & $1.00 \pm 0.11$ & $0.92 \pm 0.11$ & $2.44 \pm 0.28$ \\
A. westerdijikia & $0.82 \pm 0.08$ & $0.80 \pm 0.28$ & $0.84 \pm 0.21$ & $3.02 \pm 0.14$ \\
A. carbonarius & $1.04 \pm 0.14$ & $1.12 \pm 0.11$ & $1.25 \pm 0.21$ & $2.28 \pm 0.14$ \\
F. verticillioides & $0.62 \pm 0.21$ & $1.25 \pm 0.14$ & $1.00 \pm 0.14$ & $2.84 \pm 0.28$ \\
F. proliferatum & $0.66 \pm 0.14$ & $0.88 \pm 0.11$ & $0.82 \pm 0.11$ & $3.78 \pm 0.21$ \\
P. verrucosum & $0.82 \pm 0.21$ & $1.22 \pm 0.21$ & $1.78 \pm 0.28$ & $3.22 \pm 0.28$ \\
\hline
\end{tabular}

$\mathrm{n}=3$, S.E: standard error, DEE ${ }^{*}$ : Diethyl ether crude extract.

\section{CONCLUSION}

The current investigation highlights the potential use of M. aeroginosa as a source of antifungal compounds for application in agriculture and food industry as bio-product. Diethyl ether was the favorable solvent to extract compounds had antifungal activity from M. aeroginosa. BHT and Hexadecanoic acid, methyl ester were the main identified compounds responsible for this activity. Finally, it is recommended to use BHT form bio-source like $M$. aeroginosa as a preservative in food industry instead of synthetic BHT.

\section{Financial support and sponsorship: Nil.}

Conflict of Interests: There are no conflicts of interest.

\section{REFERENCES}

Abed R, Dobretsov, S and Sudesh K. Applications of cyanobacteria in biotechnology. J. Appl. Microbiol., 2009; 106:1-12.

Abubacker $\mathrm{N}$ and Deepalakshmi T. In vitro antifungal potentials of bioactive compound methyl ester of Hexadecanoic acid Isolated from Annona muricata Linn. (Annonaceae) Leaves. Biosci. Biotechnol. Res., 2013; 10(2), 879-884.

Ahmad B, Khan I, Bashir S and Azam S. Chemical composition and antifungal, phytotoxic, brine shrimp cytotoxicity, insecticidal and antibacterial activities of the essential oils of Acacia modesta. J. Med. Plants Res., 2012; 6(31): 4653-4659.

Al-Rekabi H. Study the effect of some algae extracts against activity of some fungi. J. Thi-Qar Univ., 2011; 4(6): 35-42.

ATCC 1984. American Type Culture Collection, 13th ed., USA, $517 \mathrm{p}$.

Bano A and Siddiqui P. Characterization of five marine cyanobacterial species with respect to their $\mathrm{pH}$ and salinity requirements, Pak. J. Bot., 2004; 36(1): 133-143.

Berry J, Gantar M, Perez M, Berry G and Noriega F. Cyanobacterial toxins as allelochemicals with potential applications as algaecides, herbicides and insecticides. Mar. Drugs, 2008; 6: 117-146.

Burja A, Banaigs B, Abou-Mansour E, Burgess J and Wright P. Marine cyanobacteria - a prolific source of natural products. Tetrahedron, 2001; 57:9347- 9377 .

Carmichael W. Health effects of toxin producing cyanobacteria: The CyanoHABs. Hum. Ecol. Risk Assess., 2001; 7:1393-1407.

Chauhan A, Chauhan G, Gupta P, Goyal P and Kaushik P. In vitro antibacterial evaluation of Anabaena sp. against several clinically significant microflora and HPTLC analysis of its active crude extracts. Indian J. Pharm., 2010; 42:105-107.

Chlipala G, Shunyan M, Esperanza J, Carcache B, Aiko I, Stanley B and Jimmy O. Investigation of antimicrobial and proteaseinhibitor activity from cultured cyanobacteria. Pharm. Biol., 2009, 47:5360 .
Chronakis I 2000. Biosolar protein from aquatic algae, In: Novel Macromolecules in Food Systems (Eds. Doxastakis, G. and Kiosseoglou, V.), Center for Chemistry and Chemical Engineering, Lund, Sweden, pp. 39-75.

Codd G 1997. Cyanobacterial blooms and toxins in fresh, brackish and marine waters. Harmful algae. Proceedings of the VIII International Conference on Harmful Algae. (Eds.). Reguera, B., J. Blanco, M. L. Fernandez and T. Wyatt: 13-17.

Colyer C, Kinkade C, Viskari P and Lan-ders J. Analysis of cyanobacterial pigments and proteins by electrophoretic and chromatographic methods. Anal. Bioanal. Chem., 2005; 382:559-569.

Demirel Z, Yilmaz-Koz F, Karabay-Yavasoglu N, Ozdemir G and Sukatar A. Antimicrobial and antioxidant activities of solvent extracts and the essential oil composition of Laurencia obtusa and Laurencia obtusa var. pyramidata. Rom. Biotech. Lett., 2011; 16:5927-5936.

Govindappa M, Prathap S, Vinay V and Channabasava R. Chemical composition of methanol extract of endophytic fungi, Alternaria sp. of Tebebuia argentea and their antimicrobial and antioxidant activity. Int. J. Biol. Pharm. Res., 2014; 5(11):861-869.

Grindberg R, Shuman C, Sorrels C, Wingerd J and Gerwick W. 2008. Neurotoxic Alkaloids from Cyanobacteria. In: Modern Alkaloids, Structure, Isolation, Synthesis and Biology. Eds. Fattorusso E and Taglialatela-Scafati O), Wiley-VCH Verlang GmbH \& Co.; Weinheim. pp. 139-170.

Hamburger $\mathrm{M}$ and Cordell G. A direct bioautography TLC assay for compounds possessing antibacterial activity. J. Nat. Prod., 1987; 50:19-22.

He F, Wang M, Gao M, Zhao M, Bai Y and Zhao C. Chemical composition and biological activities of Gerbera anandria. Molecules, 2014; 19(4):4046-4057.

Hwang $\mathrm{H}$ and Winkler-Moser J. Food additives reducing volatility of antioxidants at frying temperature. J. Amer. Oil Chem. Soci., 2014; 91(10), 1745-1761.

Jain M, Soni L, Deb A, Jain S, Rout V and Krishna K. Antioxidant and hepatoprotective activity of ethanolic and aqueous extracts of Momordica dioica Roxb. leaves. J. Ethnopharm., 2012; 115(1):61-66.

Jaiswal P, Prasanna R and Singh P. Characterization of the biocidal spectrum of extracellular filtrates of Microcystis aeruginosa. Indian J. Microbiol., 2011, 51(4):509-514.

Jassbi A, Mohabati M, Eslami S, Sohrabipour J and Miri R. Biological activity and chemical constituents of red and brown algae from the Persian Gulf. Iranian J. Pharm. Res., 2013;12 (3):339-348.

Kamble S, Rokde A and Chavan A. Antifungal activity of algal extracts against plant pathogenic fungi. Inter. Multidisciplinary Res. J., 2012; 2(3):23-24.

Khalid M, Shameel M, Ahmed V, Shahzad S and Lghani S. Studies on the bioactivity and Phycochemistry of Microcystis aeruginosa (Cyanophyta) from Sindh. Pak. J. Bot., 2010; 42(4):26352646.

Kulik M. The potential for using cyanobacteria (blue green algae) and algae in the biological control of plant pathogenic bacteria and fungi. Eur. S. Plant Path., 1995; 101 (6):585-599. 
Kumar V, Bhatnagar A and Srivastava J. Antibacterial activity of crude extracts of Spirulina platensis and its structural elucidation of bioactive compound. J. Med. Plant Res., 2011; 5:7043-7048.

Lakhsmi $\mathrm{P}$ and Rajalakshmi P. Identification of phytocomponents and its biological activities of Aloe vera (L.) through Gas Chromatography-Mass Spectrometry. Int. Res. J. Pharm., 2011; 2 (5):247249.

Li D, Yan S, Proksch P, Liang Z, Li Q and Xu J. Volatile metabolites profiling of a Chinese mangrove endophytic Pestalotiopsis sp. strain. Afr. J. Biotechnol., 2013; 12(24):3802-3806.

Madhumathi V, Deepa P, Jeyachandran S, Manoharan C and Vijayakumar, S. Antimicrobial activity of cyanobacteria isolated from freshwater lake. Int. J. Microbiol. Res., 2011; 2: 213-216.

Marimuthu M, Nagara N and Ravi D. GC-MS analysis of phytochemicals, fatty acids and antimicrobial potency of dry Christmas lima beans. Int. J. Pharm. Sci. Rev. Res., 2014; 27(2):63-66.

Marrez D, Naguib M, Sultan Y, Daw Z, Zaher S and Higazy A. Phytoplankton profile and toxicity assessment of dominant algae species from different Egyptian aquatic ecosystems. Res. J. Pharm. Biol. Chem. Sci., 2016; 7(2):1453 - 1461.

Mavi A, Yiğit N, Demet $\mathrm{Y}$ and Ali $\mathrm{K}$. Antioxidant and antimicrobial activity of Turkish endemic Sonchus erzincanicus extracts .Turk J. Biol., 2011; 35:243-250.

Mazur H, Lewandowska J, Błaszczyk A, Kot A and Pliński M. Cyanobacterial toxins in fresh and brackish waters of Pomorskie Province (Northern Poland), Oceanol. Hydrobiol. Stud., 2003; 32 (1):15-26.

Medeiros M, Oliveira D, Rodrigues D and Freitas D. Prevalence and antimicrobial resistance of Salmonella in chicken carcasses at retail in 15 Brazilian cities. Rev. Panam. Salud. Public., 2011; 30(6):555-560.

Mo S, Krunic A, Chlipala G and Orjala J. Antimicrobial ambiguine isonitriles from the cyanobacterium Fischerella ambigua. J. Nat. Prod., 2009; 72:894-899.

Mubarak D, Praveenkumar R, Shenbagavalli T, Mari T, Ahamed A, Al-Dhabi N and Thajuddin N. New reports on anti-bacterial and anti-candidal activities of fatty acid methyl esters (FAME) obtained from Scenedesmus bijugatus var. bicellularis biomass. RSC Adv., 2012; 2:11552-11556.

Mujeeb F, Bajpai P and Pathak N. Phytochemical evaluation, antimicrobial activity and determination of bioactive components from leaves of Aegle marmelos. Bio. Med. Res. Int., 2014; 4(10):1-11.

Mundt S, Kreitlow $S$ and Jansen R. Fatty acids with antibacterial activity from the cyanobacterium Oscillatoria redekei HUB 051. J. Appl. Phycol., 2003; 15:263-267.

Neuhof T, Schmieder P, Preussel K, Dieckmann R, Pham H, Bartl $\mathrm{F}$ and von Döhren, H. Hassallidin A, a glycosylated lipopeptide with antifungal activity from the cyanobacterium Hassallia sp. J. Nat. Prod., 2005; 68:695-700

Oyugi D, Ayorinde F, Gugssa A, Allen A, Izevbigie E, Eribo B and Anderson W. Biological activity and mass spectrometric analysis of Vernonia amygdalina fractions. J. Biosci. Tech., 2011, 12(3):287-304.

Pandey V, Pandey A and Sharma V. Biotechnological applications of cyanobacterial phycobiliproteins. Int. J. Curr. Microbiol. App. Sci., 20132(9):89-97.

Passone M Resnik S and Etcheverry M. The potential of food grade antioxidants in the control of Aspergillus section Flavi, interrelated mycoflora and aflatoxin B1 accumulation on peanut grains. Food Control, 2008; 19, 364-371.

Passone M, Resnik S and Etcheverry M. Potential use of phenolic antioxidants on peanut to control growth and aflatoxin B1 accumulation by Aspergillus flavus and Aspergillus parasiticus. J. Sci. Food Agric., 2007; 87, 2121-2130.

Perrucci A, Okmen A, Gulluce M, Akpulat H and Dafera D. The in vitro antimicrobial and antioxidant activities of the essential oils and methanol extracts of endemic Thymus spathulifolius. Food Contl., 2004; 15:627-634.

Perveen K and Alwathnani H. Antifungal activity of methanol, acetone and diethyl ether extracts of cyanobacteria against plant pathogenic fungi. Asian J. Chem., 2013; 25(13): 7531-7534.
Prabhadevi V, Sathish S, Johnson M, Venkatramani B and Janakiraman N. Phytochemical studies on Allamanda cathartica L. using GC-MS. Asian Pac. J. Trop. Biomed., 2012; 2(2): 550-554.

Rippka R, Deruelles J, Waterbury B, Herdman M and Stanier Y. Generic assignments, strain histories and properties of pure cultures of cyanobacteria. J. Gen. Microb., 1979; 111:1-61.

Ruan E, Aalhus J and Juárez M. A rapid, sensitive and solvent-less method for determination of malonaldehyde in meat by stir bar sorptive extraction coupled thermal desorption and gas chromatography/mass spectrometry with in situ derivatization. Rapid Communications in Mass Spectrometry, 2014; 28(24), 2723-2728.

Rybicka D. Potentially toxic blue-green algae (Cyanoprokaryota) in the Vistula Lagoon, Oceanol. Hydrobiol. Stud. 2005; 34 (3):161-176.

Saittagaroon S, Kawakishi S and Namiki M. Aroma constituents of roasted coconut. Agric. Biol. Chem., 1984; 48(9), 2301-2307.

Salem O, Hoballah E, Ghazi S and Hanna S. Antimicrobial activity of microalgal extracts with special emphasize on Nostoc sp. Life Sci. J., 2014; 11(12):752-758.

Saxena M, Faridi U, Srivastava S, Darokar M, Mishra R, Pal A, Shisodia B and Khauja S. A cytotoxic and hepatoprotective agent from Withania somnifera and biological evaluation of its ester derivatives. Nat Prod. Comm., 2007; 2:1-4.

Senthilkumar P, Sambath R and Vasantharaj S. Antimicrobial potential and screening of antimicrobial compounds of Ruellia tuberose using GC-MS. Int. J. Pharm. Sci. Rev. Res., 2013; 20 (1):184-189.

Shrivastava D. Toxicity of cyanobacteria against pathogenic bacteria and fungi. Indian J. Sci. Res., 2014, 4(1):1-7.

Silva S, Rodríguez-Borges J, Marques $\mathrm{E}$ and do Vale $\mathrm{M}$. Towards novel efficient monomeric surfactants based on serine, tyrosine and 4-hydroxyproline: synthesis and micellization properties. Tetrahedron, $2009 ; 65(21), 4156-4164$

Stewart I, Schluter $P$ and Shaw G. Cyanobacterial lipopolysaccharides and human health - a review. Environmental Health, 2006; 5:7-53.

Sultan Y, Ali M, Darwesh O, Embaby $\mathrm{M}$ and Marrez D. Influence of Nitrogen Source in Culture Media on Antimicrobial Activity of Microcoleus lacustris and Oscillatoria rubescens. Research Journal of Pharmaceutical, Biological and Chemical Sciences, 2016; 7(2): 14441452 .

Tiwari O, Singh B, Mishra U, Singh A, Wattaldhar D and Singh A. Distribution and physiological characterization of cyanobacteria isolated form arid zones of Rajasthan. Tropical Ecology, 2005; 46 (2):165171.

Tsubouchi H, Yamamoto K, Hisada K, Sakabe Y and Udagawa S. Effect of roasting on ochratoxin A level in green coffee beans inoculated with Aspergillus ochraceus. Mycopathologia, 1987; 97: 111115 .

Udgire $\mathrm{M}$ and Pathade G. Evaluation of antimicrobial activities and phytochemical constituents of extracts of Valeriana wallichii. Asian J. Plant Sci. Res., 2013; 3(5):55-59.

How to cite this article:

Marrez DA, Sultan YY. Antifungal activity of the cyanobacterium Microcystis aeruginosa against mycotoxigenic fungi. J App Pharm Sci, 2016; 6 (11): 191-198. 